\title{
Chlormethine Gel in Combination with Other Therapies in the Treatment of Patients with Mycosis Fungoides Cutaneous T Cell Lymphoma: Three Case Reports
}

\author{
Kyriaki Lampadaki · Marios Koumourtzis · Fani Karagianni · \\ Leonidas Marinos · Evangelia Papadavid
}

Received: January 25, 2021 / Accepted: March 22, 2021 / Published online: April 30, 2021

(c) The Author(s) 2021

\section{ABSTRACT}

Introduction: Chlormethine gel is a skin-directed therapy recommended for patients with early-stage mycosis fungoides (MF) cutaneous T cell lymphoma.

Methods: Herein, we present three cases of patients with stage IB-IIB MF who were treated with chlormethine gel and concomitant therapies.

Results: All patients responded well to treatment with chlormethine gel; complete responses were observed with improvements in Modified Severity-Weighted Assessment Tool scores and severity of lesions; one patient reported an improvement in quality of life. While adverse events did occur after treatment initiation, they were skin related and could be effectively managed through reductions in treatment frequency and the addition of emollients and topical steroids.

Conclusion: The cases presented here illustrate that chlormethine gel is an effective and safe treatment option for patients with MF who had received prior therapies that had proved ineffective. Chlormethine gel could be combined

K. Lampadaki · M. Koumourtzis · F. Karagianni ·

L. Marinos · E. Papadavid ( $₫)$

2nd Department of Dermatology and Venereology,

National and Kapodistrian University of Athens,

"Attikon" University General Hospital, Athens,

Greece

e-mail: papadavev@yahoo.gr with other skin-directed or systemic therapies for optimal benefit. Incidences of dermatitis were seen to be successfully managed and quality of life benefits were also reported.

Keywords: Chlormethine gel; Clinical management; Contact dermatitis; Cutaneous T-cell lymphoma; Mycosis fungoides

\section{Key Summary Points}

The data presented provide real-world evidence on the management of mycosis fungoides (MF) in daily clinical practice through the application of chlormethine gel.

Patients with stage I-IIB MF who had varying treatment histories achieved complete responses after treatment with chlormethine gel.

Skin-related adverse events (AEs) were successfully managed through the use of topical emollients and steroids.

The occurrence of skin-related AEs did not impact the decision to remain on treatment. 


\section{DIGITAL FEATURES}

This article is published with digital features, including a summary slide, to facilitate understanding of the article. To view digital features for this article, go to https://doi.org/10.6084/ m9.figshare.14248736.

\section{INTRODUCTION}

Mycosis fungoides (MF) is the most common form of cutaneous T cell lymphoma (CTCL). It is typically characterized by the infiltration of malignant $\mathrm{T}$ cells into the skin $[1,2]$ and can present with persistent patches and plaques [1], which cause symptoms such as pruritus, pain, and skin irritation. Early-stage disease follows an indolent course [3] and there are no curative options. Therapeutic strategies are aimed at local treatment of lesions, prevention of disease progression, and maintaining quality of life. However, despite treatment, patients may live with highly symptomatic lesions that result in pain and itching for years to decades. This can severely affect their quality of life and interfere with daily functioning and ability to work, as well as cause psychological distress [4].

For early-stage disease (IA-IIA), international guidelines recommend that patients are treated using skin-directed therapies [5-7]. A number of options are available including topical corticosteroids, phototherapy, and bexarotene, although not all are approved for MF and there is a lack of clear consensual treatment algorithms. Treatment choice is often influenced by a patient's preference and the anticipation of certain side effects, which often manifest as cutaneous reactions, such as skin irritation and contact dermatitis [8].

Chlormethine (CL; also known as mechlorethamine) is a skin-directed therapy recommended as a first-line treatment option for adult patients with MF [5-7]. CL was first developed in aqueous and compounded ointment formulations $[9,10]$ but these were found to present patients with challenges regarding the preparation and application of the treatment. More recently, a topical CL $0.016 \% \mathrm{w} / \mathrm{w}$ gel formulation (equivalent to $0.02 \%$ chlormethine $\mathrm{HCl}$ ) was developed specifically for the treatment of patients with MF. The gel has several advantages over the aqueous and ointment formulations. It is stable, nongreasy, and quick drying, and these properties allow it to be conveniently administered at home, which may encourage treatment compliance. While cutaneous reactions such as contact dermatitis may be seen following CL gel treatment, these can be effectively managed through treatment adjustments and the use of emollients or corticosteroids, depending on the patient's needs [11].

CL gel was approved in the USA in 2013 for the topical treatment of stage IA and IB MF in patients who have received prior skin-directed therapy, on the basis of results from the 201 registration study (NCT00168064) and 202 extension study [12-15]. Following this, CL gel was also approved in Israel in 2016 for the same indication, and in the EU in 2017 for treatment of any-stage adult patients [16]. In the pivotal 201 study, the efficacy of CL gel was shown to be noninferior to equal-strength $\mathrm{CL}$ ointment [13]. In addition, the response rates for the Composite Assessment of Index Lesion Severity (77\% for gel, 59\% for ointment) and Modified Severity-Weighted Assessment Tool (mSWAT; $63 \%$ for gel, $56 \%$ for ointment) appeared to be higher with CL gel compared with ointment. The mSWAT is a method for skin scoring that is used for patients with MF; it assesses the body surface area (BSA) of each lesion type in 12 different areas of the body. A score is then calculated by multiplying the BSA of the lesion types by a weighting factor (patch $=1$, plaque $=2$, and tumor $=4$ ) [17]).

Herein, we report a case series of patients with MF, in which we describe each patient's diagnosis, treatment history, and how they were treated in the clinic. Our intention was to use our real-world practical experience to provide guidance to dermatologists on the management of patients with MF, to illustrate the effectiveness of CL gel in treating patients with $\mathrm{MF}$, and document management strategies for emergent cutaneous side effects. To best convey this information, we report our experience as three different case studies. All patients provided written informed consent for their cases to be described and their photos to be used. 


\section{CASE 1}

The first case was a 70-year-old woman who had a 10-year history of skin lesions. The patient was diagnosed in 2014 with initial stage IB (T2bNOM0B0) folliculotropic MF and an mSWAT score of 32. While the patient had stable disease, she had lost complete response (CR) after several prior lines of therapy; a schematic of her treatment history is shown in Fig. 1a. The patient was first treated with psoralen and ultraviolet $\mathrm{A}$ in combination with clobetasol, which initially resulted in a CR. However, after 15 months the patient experienced a relapse, and treatment with $25 \mathrm{mg}$ acitretin was initiated. The patient achieved a CR from the first month, but by mid-2015 had progressed to stage IIB (T3NOMOBO) MF and presented with multiple facial tumors and follicular infiltrated plaques on the body, with an mSWAT score of 30 . Following a month of total skin electron beam therapy, a CR was observed and interferon- $\alpha$ (IFN $\alpha$ ) treatment was initiated. After the first month of IFN $\alpha$, the patient achieved a partial response (PR), the facial tumors improved, and the mSWAT decreased to 14. The patient relapsed after 22 months, presenting with persistent and new facial plaques and tumors, with an mSWAT of 36. Low-dose methotrexate was added to the treatment regimen and a PR was once again observed. After 13 months of methotrexate treatment, the patient discontinued because of the emergence of adverse events (AEs). A month later, after 3 years of treatment, IFN $\alpha$ was also discontinued because of issues with reimbursement and treatment fatigue.

In August 2019, just over a month after IFN $\alpha$ was stopped, the patient had an mSWAT score of 14 and was initiated on once-daily application of CL gel to lesions on the neck, cheek, and occipital areas. A response was observed in week 2, with some clearance of facial lesions, and the mSWAT score reduced to 11.6. Although the patient reported a "stinging" sensation after each daily application, this only lasted for approximately $10 \mathrm{~min}$. Subsequently, CL gel was also applied to the body lesions. In October 2019, acute dermatitis was diagnosed with itching on body lesions that were present on the patient's buttocks and thighs. The dose of CL gel was reduced to once every other day in response to the dermatitis, and concomitant treatment with clobetasol was initiated. The dermatitis was effectively managed, and the patient was happy to continue CL gel treatment on the body patches and plaques. The mSWAT score increased to 19.5 by the end of November 2019, so $180 \mu \mathrm{g}$ or $0.5 \mathrm{~mL}$ weekly pegylated IFN $\alpha$ was added to the treatment regimen. By February 2020, the mSWAT score had decreased to 3.25 , and decreased further still to 2.5 in September 2020. After 6-12 months of combination treatment with CL gel, clobetasol, and pegylated IFN $\alpha$, a clear improvement in the patches and plaques was observed compared with the situation prior to treatment (Fig. 1b). The dermatitis was effectively managed using only topical emollients. Treatment with CL gel, clobetasol, and pegylated IFNa is currently ongoing and the patient is happy to continue applying the gel once daily. As of October 2020, the mSWAT was 2.5 .

\section{CASE 2}

The second case documents a 55-year-old man who had progressive skin disease that was resistant to previous therapies. Lesions were initially observed in 2012 but the patient was not diagnosed until 2017, when it was confirmed that he had stage IB (T2bNOMOB0) folliculotropic MF with an mSWAT score of 36 . Treatment with a CL compound was initiated; a PR was observed within 3 weeks, with an mSWAT of 30 , although the patient subsequently progressed (Fig. 2a). In May 2018, treatment with IFN $\alpha 2 \mathrm{~B}$ was initiated and the patient had a PR with the mSWAT score decreasing to 18 within 16 weeks. After 8 months of treatment, the mSWAT score started to fluctuate between 18 and 6; clobetasol was added to the treatment regimen and resulted in short-term improvement. Clobetasol was discontinued in September 2019 and the patient received daily application of CL gel to persistent patches and plaques located on the 
a

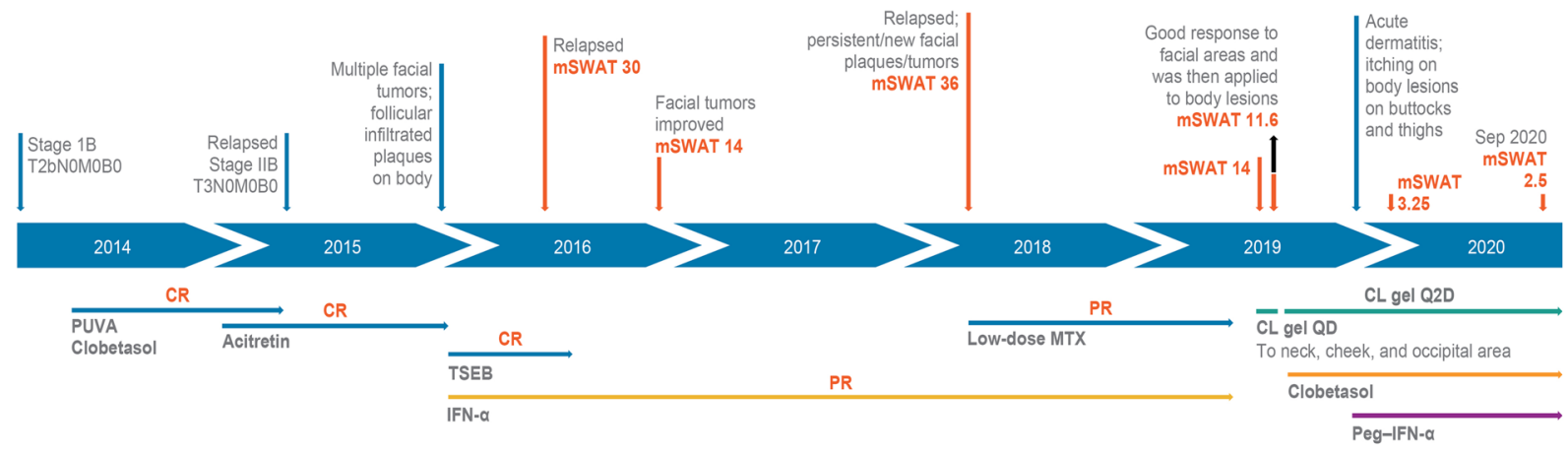

b

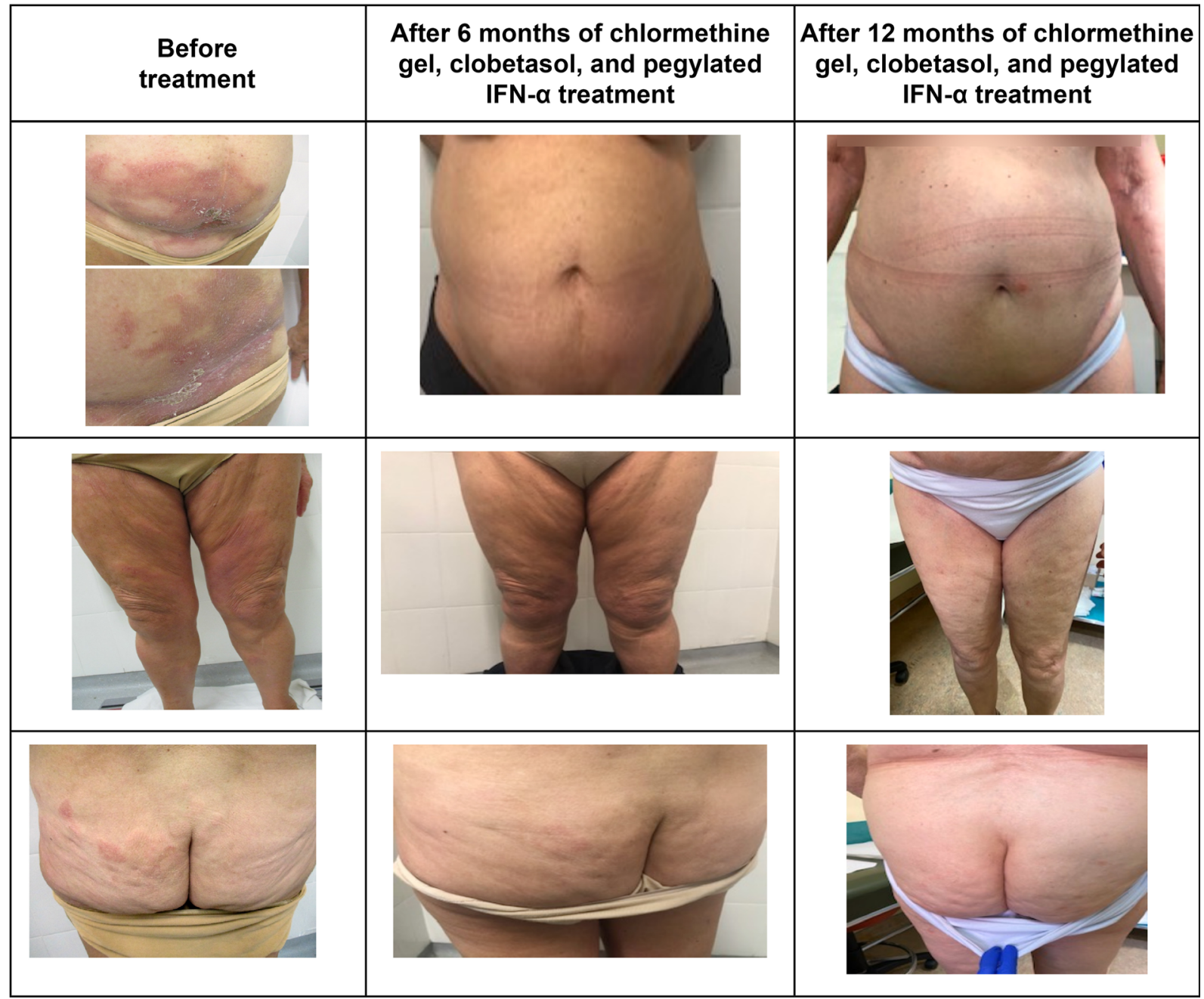

Fig. 1 Case 1-treatment history (a) and patient photos taken before and after treatment with CL gel, clobetasol, and pegylated IFN $\alpha(\mathbf{b})$. CL chlormethine, CR complete response, D day, IFN $\alpha$ interferon- $\alpha, \mathrm{mSWAT}$ Modified Severity-Weighted Assessment Tool, MTX methotrexate,
Peg pegylated, PR partial response, PUVA psoralen and ultraviolet $\mathrm{A}, \mathrm{Q}$ every, TSEB total skin electron beam 
a

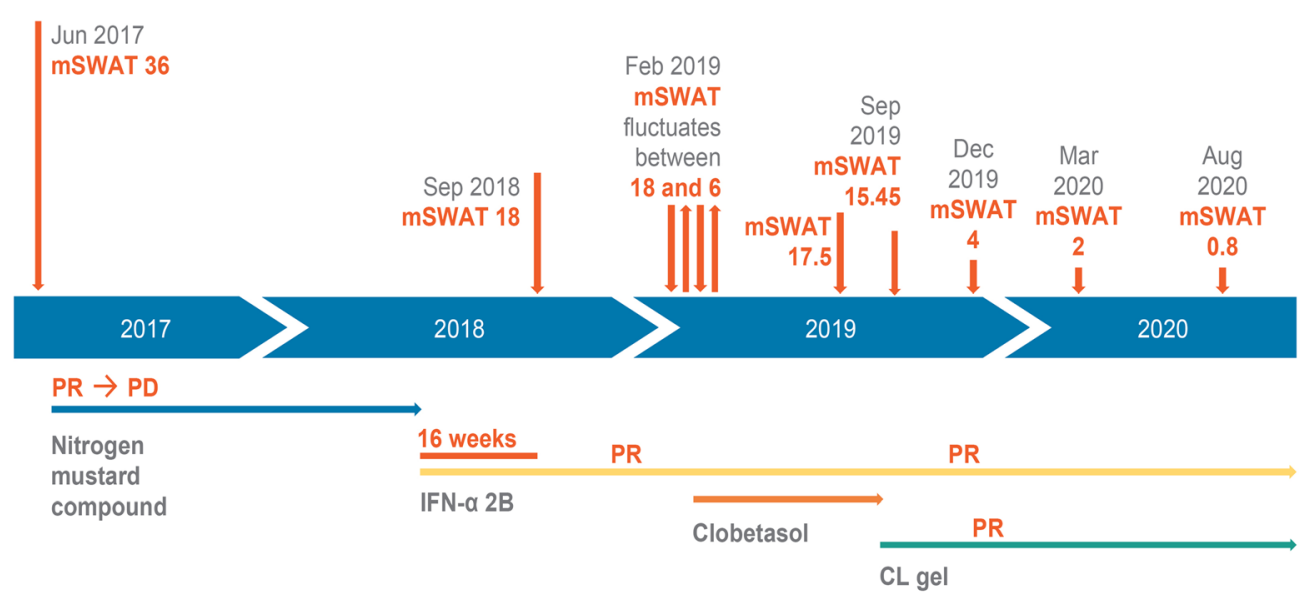

b

\begin{tabular}{|c|c|c|c|}
\hline $\begin{array}{c}\text { Before } \\
\text { treatment }\end{array}$ & $\begin{array}{c}\text { After 3 months of } \\
\text { chlormethine gel and } \\
\text { IFN- } \alpha \text { 2B treatment }\end{array}$ & $\begin{array}{c}\text { After 6 months of } \\
\text { chlormethine gel and } \\
\text { IFN- } \alpha \text { 2B treatment }\end{array}$ & $\begin{array}{c}\text { After 12 months of } \\
\text { chlormethine gel and } \\
\text { IFN- } \alpha \text { 2B treatment }\end{array}$ \\
\hline & & & \\
\hline & & & \\
\hline & & & \\
\hline
\end{tabular}


4Fig. 2 Case 2-treatment history (a) and patient photos taken before and after treatment with CL gel and IFN $\alpha 2 \mathrm{~B}$ (b). CL chlormethine, IFN $\alpha 2 \mathrm{~B}$ interferon- $\alpha 2 \mathrm{~B}, \mathrm{mSWAT}$ Modified Severity-Weighted Assessment Tool, PD progressive disease, PR partial response

trunk and arms, forearms, and thighs, with concomitant IFN $\alpha 2 \mathrm{~B}$.

After 2 months on this regimen, the mSWAT had decreased to 15.45 , with a further reduction to 4 in December. The patient continued to improve, with an mSWAT score of 2 reported in March 2020 and the lesions almost gone. In August, the patient had achieved a near CR with a further reduction of mSWAT to 0.8 (Fig. 2b). Erythema was observed in the first month of treatment, but this was managed with emollients and no itching occurred. Skin hyperpigmentation occurred after 6 months of treatment. Treatment is ongoing and the mSWAT score remains at 0.8 . In addition, the patient is happy and has reported better quality of life; this was assessed by the three-dimensional, dermatology-specific, health-related quality of life Skindex-29 score questionnaire [18-21], which the patient completed at least two or three times a year on his visits to the clinic.

\section{CASE 3}

The third case concerns a 66-year-old man who had a 5-year history of skin lesions. He presented with multiple tumors on the neck, anterior trunk, and forearms, as well as infiltrated plaques on the trunk and extremities. The patient was diagnosed in 2018 with initial stage IIB (T3NOMOB0) folliculotropic MF with an mSWAT score of 36 . The first-line therapy for this patient was IFNa 2B plus clobetasol (Fig. 3a). A PR was observed and within 3 months, the mSWAT had decreased to 6 . After receiving IFN $\alpha 2 \mathrm{~B}$ for 9 months, the treatment was discontinued because of issues with reimbursement. The patient was subsequently treated with low-dose methotrexate for 3 months, but no response was observed, and the patient had progressive disease. By the end of August
2019, the mSWAT was 5.9 and in September treatment with CL gel once daily and pegylated IFN $\alpha 2 \mathrm{~A}(180 \mu \mathrm{g})$ was initiated. After 3 months of this regimen, a PR was observed and the mSWAT score had decreased to 1.08. After a further 3 months of treatment the patient achieved a CR with an mSWAT of 0.45 . The response continued and by July 2020, the mSWAT was 0. Skin irritation was experienced in the first month of CL gel treatment but was effectively managed through the use of topical steroids, reducing the application frequency of CL gel to once every 3 days, and ensuring the patient was adequately hydrated (Fig. 3b). Skin hyperpigmentation was observed after 6 months of treatment. As of September 2020, the patient still had a CR, with an mSWAT score of 0 , and continues to apply CL gel once a week concurrent with daily pegylated IFN $\alpha 2 \mathrm{~A}$ and emollients.

\section{DISCUSSION}

Herein, we describe three patients with different stages of MF, each of whom benefited from CL gel treatment after either having no response or losing response to prior therapies. Each patient had clear improvements in their skin lesions and mSWAT scores after initiating CL gel treatment. One patient with stage IIB MF achieved a CR with an mSWAT of 0 .

All patients used CL gel in combination with other therapies. While the pivotal 201 study showed the efficacy of CL gel monotherapy [13], in daily clinical practice the gel is often used as part of a combinatorial regimen. The prospective, observational PROVe study investigated the use of CL gel in real-life practice in the USA [22]. In total, $78 \%$ of patients used other skin-directed therapies in combination with CL gel and 30\% of patients used concomitant systemic therapies. The most common skin-directed and systemic therapies were topical corticosteroids $(60 \%)$ and oral bexarotene (16\%), respectively. Furthermore, a report from the Jefferson Multi-Disciplinary Cutaneous Lymphoma Clinic also indicated that CL gel is generally used in combination with other therapies, including class 1 topical steroids, 


\section{a}

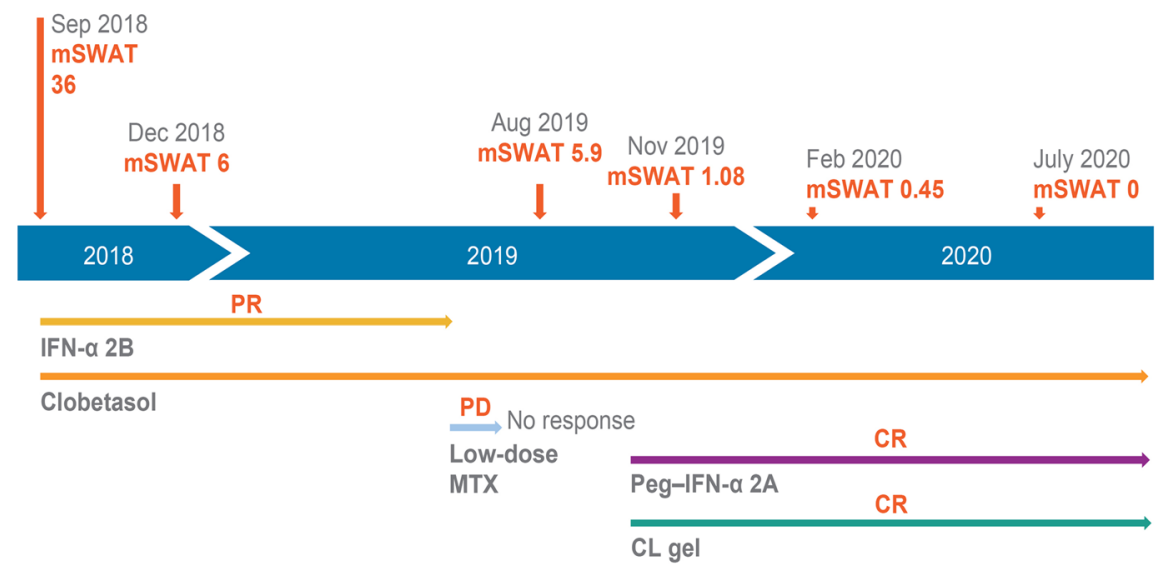

b

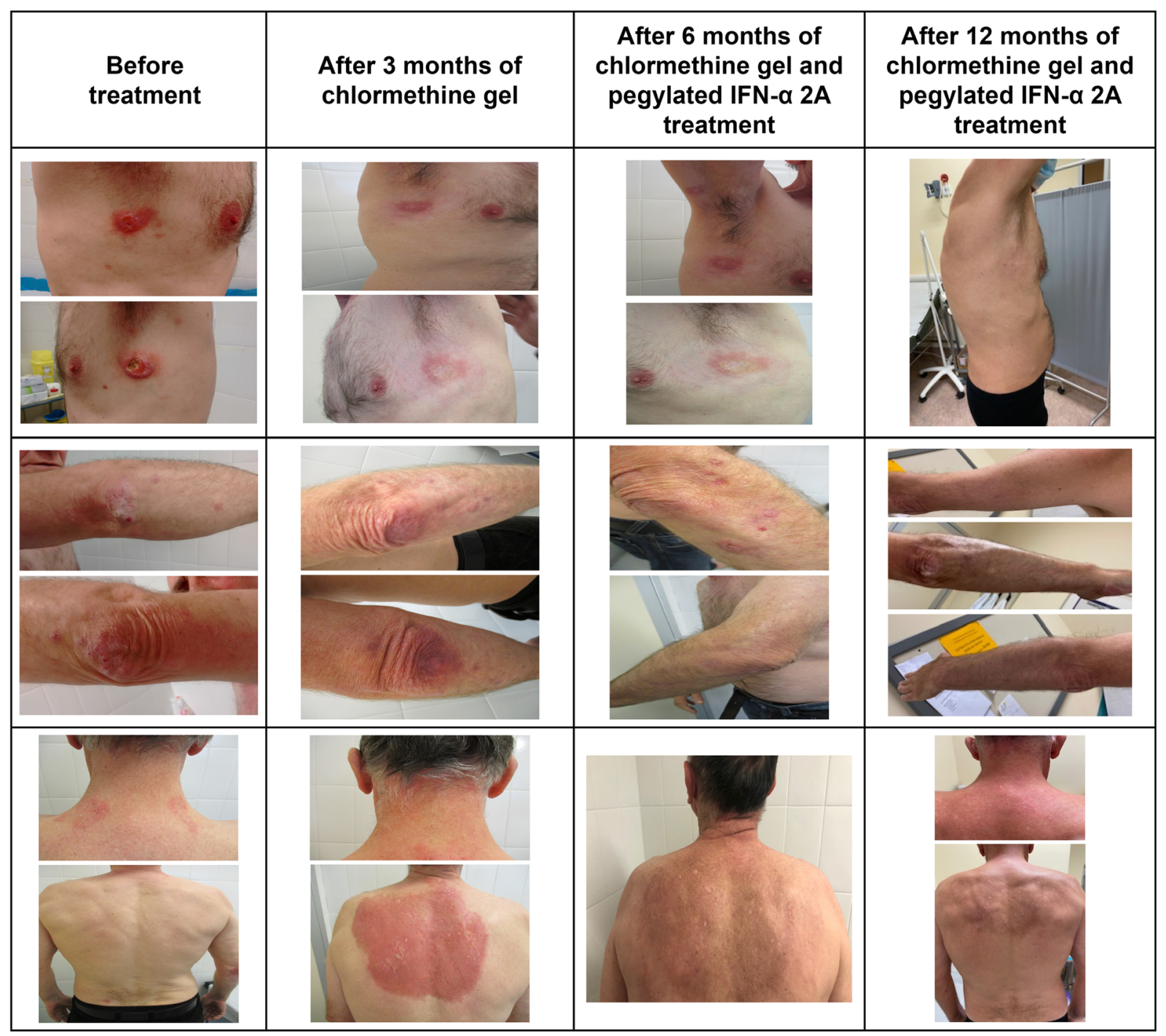


4 Fig. 3 Case 3-treatment history (a) and patient photos taken before and after treatment with $\mathrm{CL}$ gel and pegylated IFN $\alpha(\mathbf{b})$. CL chlormethine, CR complete response, IFN $\alpha 2 \mathrm{~B}$ interferon- $\alpha 2 \mathrm{~B}, \mathrm{mSWAT}$ Modified Severity-Weighted Assessment Tool, MTX methotrexate, PD progressive disease, Peg pegylated, PR partial response

narrowband ultraviolet $\mathrm{B}$, psoralen and ultraviolet A, imiquimod, and pimecrolimus [23]. In all three cases presented here, CL gel was combined with IFN $\alpha$ treatment. IFN $\alpha$ in combination with skin-directed therapies is a recommended treatment option for patients with more-advanced stages of disease [6]. To our knowledge, no real-world data on the use of CL gel in combination with IFN $\alpha$ have been published. A recently published study, which analyzed serum samples from the 201 and 202 studies, investigated whether CL gel was systemically absorbed when applied to the skin. Results indicated no evidence of systemic absorption in any samples taken for up to 6 months after treatment initiation. These findings indicate that drug-drug interactions are highly unlikely when CL gel is combined with systemic agents such as IFN $\alpha$ [24]. Indeed, the cases reported herein demonstrate the safety and efficacy of CL gel and IFN $\alpha$ treatment.

While skin-related AEs were experienced by each patient after the initiation of CL gel treatment, they could be effectively managed by adding topical emollients, steroids, or reducing the CL gel dose. This is in line with published data [11]. Appropriate management of these AEs is critical for optimal disease management. This allows patients to continue treatment, which is important, as late responses to CL gel treatment (after more than 6 months) are not uncommon [25].

For two patients, the application frequency of CL gel was reduced to once every 2 or 3 days, but this reduction in application frequency did not appear to alter the response. Similar dose reductions were also reported in the PROVe study, where lower treatment frequencies of CL gel were quite common [22]. Many patients who experience mild-to-moderate hypersensitivity reactions after initiation of CL gel can continue treatment after intervention. Even patients who have severe skin reactions can restart treatment at lower frequencies to test tolerance and may be able to continue treatment [11]. Moreover, there is evidence to suggest that the development of cutaneous reactions, such as contact dermatitis, does not impact the response to CL gel $[11,26]$ and in some instances has led to earlier clearance of the lesion(s) [27].

In conclusion, our cases demonstrate the effectiveness and tolerability of CL gel in patients with stage IB and stage IIB MF, and illustrate how responses may be achieved in patients who have previously received multiple lines of therapy with limited responses. Each of the patients described herein was using CL gel in combination with IFN $\alpha$, thus our data indicate the suitability of this combination for the treatment of MF. The treatment-emergent AEs were seemingly mild in nature and could be effectively managed with the appropriate topical interventions. While the observations seen in this case series are very interesting and it is hoped they will aid clinical practice decisions, results from this limited number of cases cannot necessarily be considered representative for all patients with MF. Clinical practice experience has shown that CL gel is used both as a first-line skin-directed therapy for early-stage MF-CTCL and as an adjunctive therapy at different disease stages, and suggests that the risks and benefits associated with CL gel contribute to the achievement of effective clinical responses.

\section{ACKNOWLEDGEMENTS}

The authors would like to acknowledge and thank the patients whose cases have been reported. The authors are fully responsible for all content and editorial decisions for this manuscript.

Funding. The Rapid Service Fee was funded by Helsinn Healthcare SA. Editorial and medical writing assistance was funded by Helsinn Healthcare SA. 
Medical Writing and Editorial Assistance. Editorial assistance in the preparation of this article was provided by Joanne Franklin, PhD, CMPP, of Aptitude Health. Support for this assistance was funded by Helsinn Healthcare SA.

Authorship. All named authors meet the International Committee of Medical Journal Editors (ICMJE) criteria for authorship for this article, take responsibility for the integrity of the work as a whole, and have given their approval for this version to be published.

Authorship Contributions. Concept: K Lampadaki, M Koumourtzis, F Karagianni, L Marinos, E Papadavid. Collection of the data: $\mathrm{K}$ Lampadaki, M Koumourtzis, F Karagianni, L Marinos, E Papadavid. Drafting of the article or critical revision of the article for important intellectual content: $\mathrm{K}$ Lampadaki, $\mathrm{M}$ Koumourtzis, F Karagianni, L Marinos, E Papadavid.

Prior Presentation. These data have been previously presented in part at the 29th European Academy of Dermatology and Venereology Congress held virtually between 29 and 31 October.

Disclosures. Kyriaki Lampadaki, Marios Koumourtzis, Fani Karagianni, Leonidas Marinos: Nothing to disclose. E. Papadavid: Lecturer: Helsinn, Mallinckrodt, AbbVie, Janssen, Novartis.

Compliance with Ethics Guidelines. All patients provided written informed consent for their cases to be described and their photos to be used. There was no involvement of the patients other than being treated for their condition.

Data Availability. Data sharing is not applicable to this article as no datasets were generated or analyzed during the current study.

Open Access. This article is licensed under a Creative Commons Attribution-NonCommercial 4.0 International License, which permits any non-commercial use, sharing, adaptation, distribution and reproduction in any medium or format, as long as you give appropriate credit to the original author(s) and the source, provide a link to the Creative Commons licence, and indicate if changes were made. The images or other third party material in this article are included in the article's Creative Commons licence, unless indicated otherwise in a credit line to the material. If material is not included in the article's Creative Commons licence and your intended use is not permitted by statutory regulation or exceeds the permitted use, you will need to obtain permission directly from the copyright holder. To view a copy of this licence, visit http://creativecommons.org/licenses/by$\mathrm{nc} / 4.0 /$.

\section{REFERENCES}

1. Willemze R, Cerroni L, Kempf W, et al. The 2018 update of the WHO-EORTC classification for primary cutaneous lymphomas. Blood. 2019;133: 1703-14.

2. Hodak E, Amitay-Laish I. Mycosis fungoides: a great imitator. Clin Dermatol. 2019;37:255-67.

3. Diamandidou E, Cohen PR, Kurzrock R. Mycosis fungoides and Sezary syndrome. Blood. 1996;88: 2385-409.

4. Sampogna F, Frontani M, Baliva G, et al. Quality of life and psychological distress in patients with cutaneous lymphoma. Br J Dermatol. 2009;160: 815-22.

5. Willemze R, Hodak E, Zinzani PL, Specht L, Ladetto M, ESMO Guidelines Committee. Primary cutaneous lymphomas: ESMO Clinical Practice Guidelines for diagnosis, treatment and follow-up. Ann Oncol. 2018;29:30-40.

6. Trautinger F, Eder J, Assaf C, et al. European Organisation for Research and Treatment of Cancer consensus recommendations for the treatment of mycosis fungoides/Sézary syndrome-update 2017. Eur J Cancer. 2017;77:57-74.

7. National Comprehensive Cancer Network. NCCN Clinical Practice Guidelines in Oncology (NCCN Guidelines ${ }^{\circledR}$ ). Primary cutaneous lymphomas. Version 1. 2020. https://www.nccn.org/professionals/ physician_gls/default_nojava.aspx. Accessed Dec 4 2020 
8. Tarabadkar ES, Shinohara MM. Skin directed therapy in cutaneous T-cell lymphoma. Front Oncol. 2019;9:260.

9. Vonderheid EC, Tan ET, Kantor AF, Shrager L, Micaily B, Van Scott EJ. Long-term efficacy, curative potential, and carcinogenicity of topical mechlorethamine chemotherapy in cutaneous $\mathrm{T}$ cell lymphoma. J Am Acad Dermatol. 1989;20:416-28.

10. Ramsay DL, Meller JA, Zackheim HS. Topical treatment of early cutaneous T-cell lymphoma. Hematol Oncol Clin N Am. 1995;9:1031-56.

11. Gilmore ES, Alexander-Savino CV, Chung CG, Poligone B. Evaluation and management of patients with early-stage mycosis fungoides who interrupt or discontinue topical mechlorethamine gel because of dermatitis. JAAD Case Rep. 2020;6:878-81.

12. Valchlor (mechlorethamine) gel [prescribing information]. Iselin, NJ: Helsinn Therapeutics (U.S.), Inc. ; 2020. https://www.accessdata.fda.gov/drugsatfda docs/label/2020/202317s009lbl.pdf. Accessed $1 \overline{9}$ Jan 2021

13. Lessin SR, Duvic M, Guitart J, et al. Topical chemotherapy in cutaneous T-cell lymphoma: positive results of a randomized, controlled, multicenter trial testing the efficacy and safety of a novel mechlorethamine, $0.02 \%$, gel in mycosis fungoides. JAMA Dermatol. 2013;149:25-32.

14. Kim YH, Duvic M, Guitart J, Lessin S. Efficacy and safety of mechlorethamine (MCH) $0.04 \%$ gel in mycosis fungoides (MF) after treatment with topical MCH 0.02\%. J Clin Oncol. 2014;32:9093.

15. Talpur R, Venkatarajan S, Duvic M. Mechlorethamine gel for the topical treatment of stage IA and IB mycosis fungoides-type cutaneous T-cell lymphoma. Expert Rev Clin Pharmacol. 2014;7: 591-7.

16. Ledaga [summary of product characteristics]. Dublin, Ireland: Helsinn Pharmaceuticals Ltd.; 2019. https://www.ema.europa.eu/en/documents/ product-information/ledaga-epar-productinformation_en.pdf. Accessed 19 Jan 2021

17. Olsen EA, Whittaker S, Kim YH, et al. Clinical end points and response criteria in mycosis fungoides and Sézary syndrome: a consensus statement of the International Society for Cutaneous Lymphomas, the United States Cutaneous Lymphoma Consortium, and the Cutaneous Lymphoma Task Force of the European Organisation for Research and Treatment of Cancer. J Clin Oncol. 2011;29:2598-607.
18. Chren MM, Lasek RJ, Quinn LM, Mostow EN, Zyzanski SJ. Skindex, a quality-of-life measure for patients with skin disease: reliability, validity, and responsiveness. J Invest Dermatol. 1996;107: 707-13.

19. Chren MM, Lasek RJ, Flocke SA, Zyzanski SJ. Improved discriminative and evaluative capability of a refined version of Skindex, a quality-of-life instrument for patients with skin diseases. Arch Dermatol. 1997;133:1433-40.

20. Chren MM, Lasek RJ, Quinn LM, Covinsky KE. Convergent and discriminant validity of a generic and a disease-specific instrument to measure quality of life in patients with skin disease. J Invest Dermatol. 1997;108:103-7.

21. De Korte J, Mombers FMC, Sprangers MAG, Bos JD. The suitability of quality-of-life questionnaires for psoriasis research: a systematic literature review. Arch Dermatol. 2002;138:1221-7.

22. Kim EJ, Geskin L, Guitart J, et al. Real-world experience with mechlorethamine gel in patients with mycosis fungoides-cutaneous lymphoma: preliminary findings from a prospective observational study. J Am Acad Dermatol. 2020;83:928-30.

23. Duffy R, Jennings T, Sahu J. Mechlorethamine gel usage in patients with mycosis fungoides in a lymphoma clinic. Indian J Dermatol. 2020;65:237-9.

24. Querfeld C, Geskin LJ, Kim EJ, et al. (2021) Lack of systemic absorption of topical mechlorethamine gel in patients with mycosis fungoides cutaneous T-cell lymphoma. J Invest Dermatol. S0022-202X(20)32402-7

25. Geskin LJ, Kim EJ, Angello JT, Kim YH. Evaluating the treatment patterns of chlormethine/mechlorethamine gel in patients with stage I-IIA mycosis fungoides: by-time reanalysis of a randomized controlled phase 2 study. Clin Lymphoma Myeloma Leuk. 2021;21(119-24):e4.

26. Ramsay DL, Parnes RE, Dubin N. Response of mycosis fungoides to topical chemotherapy with mechlorethamine. Arch Dermatol. 1984;120: 1585-90.

27. Kim YH, Martinez G, Varghese A, Hoppe RT. Topical nitrogen mustard in the management of mycosis fungoides: update of the Stanford experience. Arch Dermatol. 2003;139:165-73. 